\title{
Experience in Asteroid Search using Astrometrica Software
}

\author{
Junior Ascencio-Moran ${ }^{1}$, Jhon Calero-Juarez ${ }^{2}$, Maria del Carmen Pajares-Acuña ${ }^{3}$, Avid Roman-Gonzalez ${ }^{4}$ \\ Image Processing Research Laboratory (INTI-Lab) \\ Universidad de Ciencias y Humanidades \\ Lima, Peru
}

\begin{abstract}
The present work of this research consists of the analysis of telescopic images provided by the International Astronomical Search Collaboration (IASC) to find asteroids that can be named. The concern in searching for asteroids helps the scientific community that promotes the collaboration of young students and astronomy fans get experience in finding asteroids through campaigns related to these. The Space Generation Advisory Council (SGAC) campaign in partnership with IASC has found around 1500 asteroids since the beginning of October 2006 as each year more than 1000 teams from different countries participate. The Astrometrica software was used which is in charge of receiving the images in FITS format. The configuration of the selected telescope is carried out so that they are later analyzed in greater detail. Finally, a clean and precise Minor Planet Center (MPC) report is made, which is what the campaign requires so that it can go on to a preliminary phase and subsequently be accepted by the international astronomical union. The asteroids that become named will be registered in the catalog of official minor planets of the world. In the campaign related to this study, one finds 28 possible asteroids.
\end{abstract}

\section{Keywords-SGAC; IASC; INTI-Lab; UCH; MPC; asteroids}

\section{INTRODUCTION}

Currently, the study and monitoring of asteroids in our Solar System represent a primary need since these celestial bodies are potential threats for the Earth. If they collide with our planet, this will imply, depending on the dimensions and internal structure of the asteroid, disasters of enormous proportions until the extinction of life on Earth [1]. On the other hand, asteroids contain a large amount of information because most of these were formed along with our Solar System and even some precede the formation of our planetary system. So, it is essential to learn from them through observations and research because these minor planets can provide us with information on the origin of evolution and life itself [2][3].

A comet is one minor solar system body, made up of a nucleus "dirty ice" that dirty snowball which we call Comet, which is made up of $\mathrm{CH}, \mathrm{CN}$ y $\mathrm{NH} 2$. When approaching the Sun given the material that makes comets, the evaporation of these compounds is sublimated, so it gives rise to a gaseous sphere called coma and dust particles and ions (triggered by the solar wind) that form the tail. This tail has a length of millions of kilometers [4].

A meteorite is the wake of light left by a meteoroid when it enters into Earth's atmosphere. The purpose of this work is to raise awareness of the importance of participating in an asteroid search campaign, in addition to telling the experience and how the campaign is developed week by week until the culmination of it, presenting real data provided by the International Astronomical Search Collaboration. Particles, scattered throughout space, are grouped in swarms and associated with a comet. Meteors are usually more visible from Earth than asteroids or comets. They are commonly known as shooting stars [4].

Asteroids are small rocky bodies compared to the planets of our solar system. Asteroids have irregular shapes, and only a small part has a spherical shape, their surfaces are full of craters or holes. The vast majority of asteroids are concentrated in the "Asteroid Belt" which is located between the Mars and Jupiter planets, also have an orbit around the Sun [5][6].

Asteroids can be discovered and observed with the help of optical telescopes by astronomers and amateurs who are passionate about asteroids and outer space. Currently, some organizations promote initiative and interest in knowledge and research; also offer the possibility of making their discoveries by participating in asteroid search campaigns.

Prestigious organizations, such as the Space Generation Advisory Council (SGAC) and the International Astronomical Search Collaboration (IASC) works together to promote space science. The Space Generation Advisory Council (SGAC) is a worldwide organization representing students and young professionals involved and interested in the space industry. The International Astronomical Search Collaboration (IASC) is a citizen science program that provides high-quality astronomical data to citizen scientists from around the world.

These citizen scientists can make original astronomical discoveries and participate in practical astronomy, that they regularly sponsor these asteroid search campaigns where only a few teams are selected from multiple schools and participants from various parts of the world. The experience of participating in this campaign also gives participating organizations the privilege of assigning a name to their discoveries.

Since the beginning of October 2006, more than 1500 asteroids have been discovered, of which 52 have been numbered by the International Astronomical Union [7]. The numbered asteroids are recorded in the catalog of official minor planets of the world. This task could be possible with the help of Astrometrica software that allows the superposition and 
analysis of images and the ability to easily compare astronomical captures to promote the discovery of objects [8].

Many of these experiences are recorded in documents describing how the process has been, as presented in this document "in search of new asteroids or Astronomy Education Review"[9] [10].

The purpose of this work is to publicize the importance of participating in an asteroid search campaign, also, to tell the experience and how the campaign develops week by week until the culmination of it, presenting real data provided by the International Astronomical Search Collaboration (IASC).

In the second part, the selection process determined by Space Generation Advisory Council (SGAC) to designate the participating teams will be addressed. It will also explain how the preparation process is developed for optimum performance during the period of the campaign, as well as indicating the characteristics of the materials necessary for this process of preparation and development of the campaign. In the third part, it will be presented how the campaign was developed during the 30 days of its duration, the results obtained from experience and how they contribute to the scientific community that is dedicated to working related to the space industry.

\section{Methodology}

To be part of the search asteroid campaign is indispensable, in the first instance, go through a selection process and, subsequently, a period of preparation before the start of the event. This section will be followed by a detailed presentation of how these procedures were developed and how they were tackled, to obtain the privilege of participating in the "SGAC Asteroid Search Campaign.

\section{A. Selection Process}

The announcement for the selection of participants of the campaign "SGAC Asteroid Search Campaign," was launched in early October 2018 by the Space Generation Advisory Council, hence the name of the search campaign. The Space Generation Advisory Council (SGAC) raised four requirements, from which teams would be chosen to form part of the asteroid search campaign. The following criteria are indicated:

- Teams should be created with a minimum of 3 and a maximum of 5 members. In the case of participants who did not have a team, there was the possibility of being associated with other participants who were in the same condition to form a team with the established requirements.

- Each team member should be registered as a Space Generation Advisory Council (SGAC) member.

- Each team member had to answer the following questions, explaining the reasons that encouraged to participate:

- Why do you want to be part of this campaign?
- How do you think that participation in the Asteroid Search Campaign could benefit you?

- Participants ' registrations should be made before the deadline established (21 October 2018).

Teams were selected based on the individual responses of each member and their regional distribution in the globe.

Based on our capacity as an enthusiastic student on research, knowledge, discoveries and countless hidden mysteries, samples of our answers to the questions set by Space Generation Advisory Council (SGAC) are shown below:

- The outer space has always been a subject of my interest because I consider that there lies the response of the origin of life and the universe. I find also exciting the opportunity to discover an asteroid by myself and to know a little more carefully about asteroids in detail. Also, I consider it an excellent opportunity to develop a new academic experience.

- I believe that participating in this campaign is essential because it represents a unique opportunity and will allow me to acquire new knowledge related to the asteroids in general. Also, have access to real data, analyze them and be able to find at least one asteroid and be able to give it a name would be rewarding.

The outer space is a privileged place and therefore deserves dedication and commitment, also, every minimum possibility of being able to get involved and contribute directly or indirectly to issues related to the space industry. It's comfortable.

As seen in the Fig. 1, the selected participants were: Calero Juarez Jhon David, Ascencio Moran Junior Angel, and Pajares Acuña Maria del Carmen under the supervision of Prof. Ph.D. Ing. Avid Roman-Gonzalez.

As seen in Table I, the selected team, which subsequently, they are notified via email on October 26; after that, each team will have four days to perform their training before asteroid hunting.

In this selection process, 17 countries participated, and there were a total of 24 teams selected.

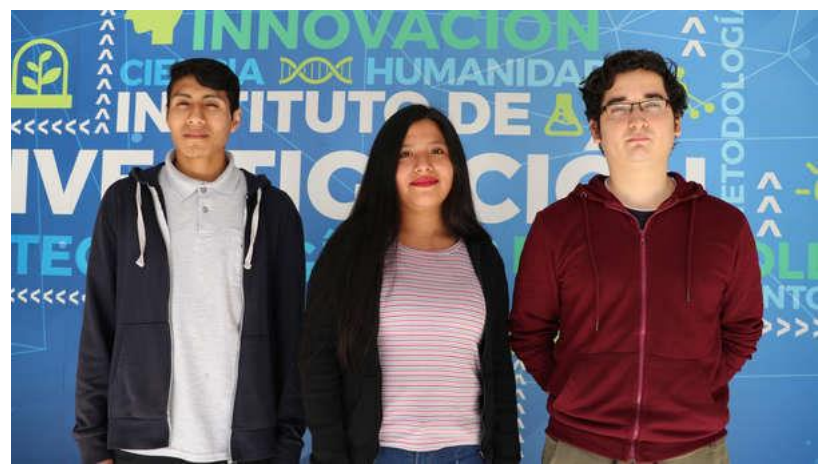

Fig. 1. Students for the Asteroid Search Campaing. 
TABLE I. PARTICIPATING TEAMS

\begin{tabular}{|c|c|c|}
\hline$\#$ & Team & Country \\
\hline 1 & Space Girls & Belarus \\
\hline 2 & Universidad Mayor de San Andres & Bolivia \\
\hline 3 & $\begin{array}{l}\text { Municipal center for } \\
\text { extracurricular activities }\end{array}$ & Bulgaria \\
\hline 4 & Candor Chasma Team & Colombia \& Peru \\
\hline 5 & Asteroid Caretakers Squad & Colombia-Bolivia \\
\hline 6 & Ryan's Belt & $\begin{array}{l}\text { Czech Republic/Slovakia/United } \\
\text { Kingdom }\end{array}$ \\
\hline 7 & YEHA & Ethiopia \\
\hline 8 & The Harwoods & France \\
\hline 9 & $\begin{array}{l}\text { Aristotle University of } \\
\text { Thessaloniki }\end{array}$ & Greece \\
\hline 10 & SAKED in Space & Greece \\
\hline 11 & STAR & Greece \\
\hline 12 & Gagan & India \\
\hline 13 & Chaitanya Mandala & Italy \\
\hline 14 & $\begin{array}{l}\text { Rock Hunters Trio - Bologna } \\
\text { University }\end{array}$ & Italy \\
\hline 15 & Astro Cypriots - Bekirpasa Lycee & North Cyprus \\
\hline 16 & $\begin{array}{l}\text { INTI-Lab - Universidad de } \\
\text { Ciencias y Humanidades }\end{array}$ & Peru \\
\hline 17 & AstropILO & Philippines \\
\hline 18 & Institute Of Astronomy Sri lanka & Sri Lanka \\
\hline 19 & Sky Trailblazers & Sri Lanka \\
\hline 20 & ULKA & Sri Lanka \\
\hline 21 & University of Khartoum & Sudan \\
\hline 22 & Azteroids & USA \\
\hline 23 & Paco to the Stars & USA \\
\hline 24 & HSU & USA \\
\hline
\end{tabular}

\section{B. Training Process}

Each team receives a unique set of images that they must then study using the Astrometric software, then prepare a report according to the Minor Planet Center (MPC) that will be sent to Dr. Patrick Miller via email. The report will then be reviewed by the International Astronomical Search Collaboration (IASC) Data Reduction Team (IDaRT) for possible discoveries and reported to the Minor Planet Center (MPC) (Harvard).

The images analyzed are provided by the Institute for Astronomy (IFA) at the University of Hawaii. These images are in FITS (Flexible Image Transport Setting) format and are captured by the $1.8 \mathrm{~m}$ Pan-STARRS telescope located in Haleakala.

The training begins as soon as the acceptance email is received, this email contains a series of instructions, a user name and a password necessary for the development of the campaign, also includes the email of five experts in the management of the software Astrometrica, who will resolve possible doubts in this regard.

Each team member is assigned a license and a password (well apart from the user password) for unlimited use of the Astrometric software. The software can be downloaded for free from the official IASC website. Also, it is possible to download a quick guide to use the software and a set of images to practice during the four days before the start of the campaign.

The success of each participating team depends on being able to use the software effectively, prepare accurate MPC reports and distinguish between right asteroids and false targets.

\section{Materials and Equipments}

To develop the search for asteroids, the Universidad de Ciencias y Humanidades through the Image Processing Research Laboratory (INTI-Lab) provided us with a laboratory with the following characteristics:

A Core i7 6th generation computer with 16RAM DDR 4, so that our team does not have difficulties when installing the program Astrometrica.

Thanks to this collaboration, we were able to carry out the asteroid search without any complications.

\section{Asteroid Search with Astrometrica Software}

During the campaign, the Astrometrica software will be used, which can be accessed for free and even provide a manual from its official website, but only the participants of this campaign will be given a user name and password with which they will receive previously after the preparation process.

To develop this experience, it is necessary to download the set of instructions provided by the campaign.

The following steps must be followed:

Step 1: As seen in the Fig. 2 unzip the archive of satellite images and place them in a folder (previously created) with the same name as the downloaded file, then open the Astrometric software and wait a few minutes until it is finished initializing (two windows will open, which must remain open throughout the process of analyzing the images).

Step 2: As seen in the Fig. 3, it is verified that the telescope (Pan-STARrs-2) selected in the software is the same as the one used to capture the images.

Step 3: As seen in the Fig. 4, one proceed to load the PanSTARRS-2 telescopic images (all images in the folder must be selected).

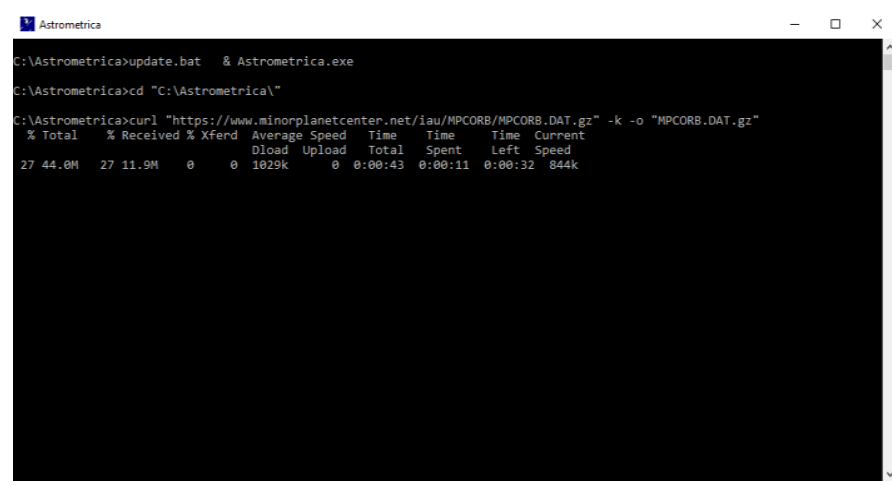

Fig. 2. Minor Planet Center (MPC) Database Update Window. 


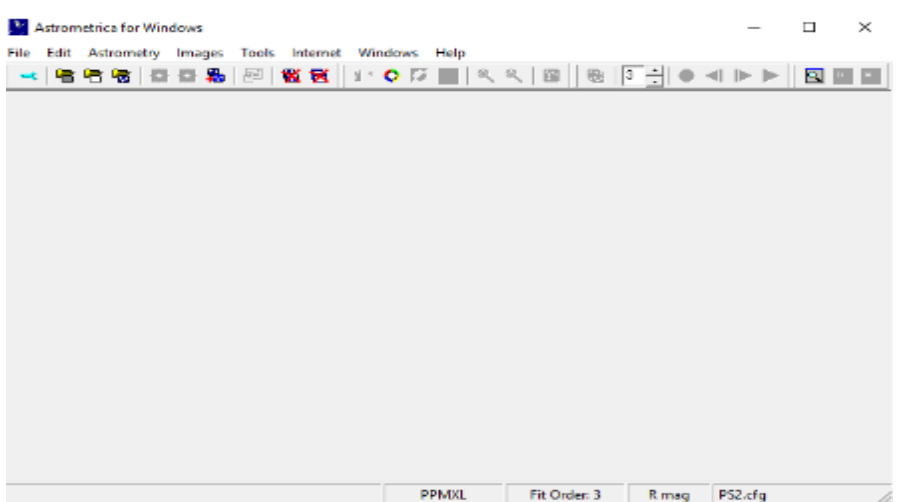

Fig. 3. Window of the Software Astrometrica, Pan-STARRS-2.

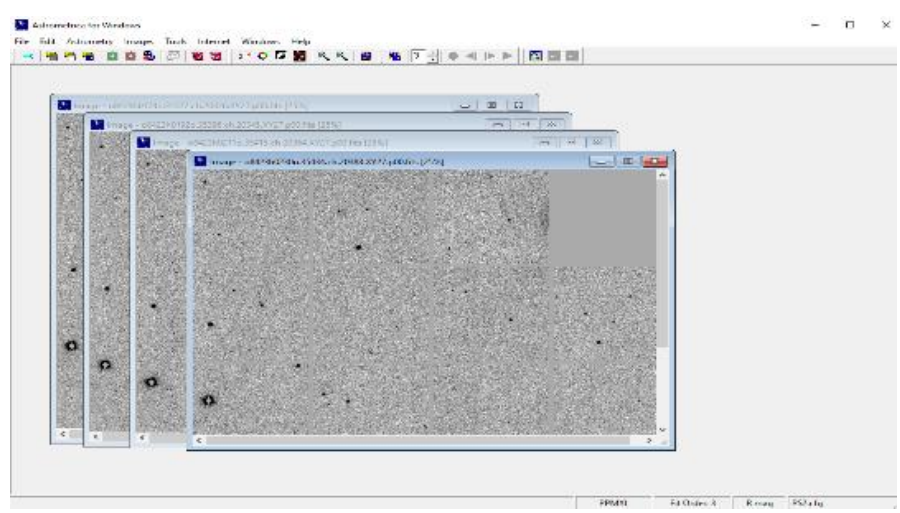

Fig. 4. Astrometric Software Window, Pan-STARRS-2 Telescope Images.

Step 4: As seen in Fig. 5, one proceed to load the PanSTARRS-2 telescopic images (all images in the folder must be selected).Select in the menu bar the icon "Astrometric Data Reduction" to highlight the stars present in the images.

Step 5: As seen in Fig. 6, select in the menu bar the icon "Known Object Overlay" to highlight the objects that have movements in the image. Then select the "Blink current images" icon so that the software can create a small gif by placing the images in succession and thus identify the moving objects present in the set of images.

Step 6: In the new window a kind of "gif" is shown where we will proceed to look for objects that present movement. In the case of locating a moving object, we should pause the "blinked" and place the pointer as close as possible to the center of the object. After this, a new window will open with the characteristics of the selected object.

As seen in Fig. 7, one must take into account the following considerations to recognize the right asteroid:

- The white dots displayed in the verification window should be distributed very close to the red line.

- The signal to noise ratio (SNR) must be greater than 5 .

- The declination and right ascension of the object should be very close to 0.00 .

- The selected object must maintain a straight line movement.

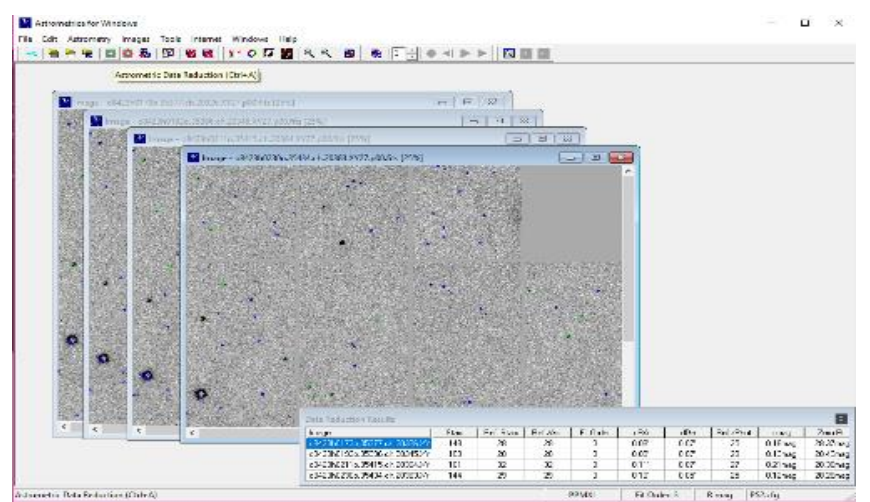

Fig. 5. Window of the Astrometrica Software, Stars Present in the Images of the Pan-STARRS-2 Telescope.

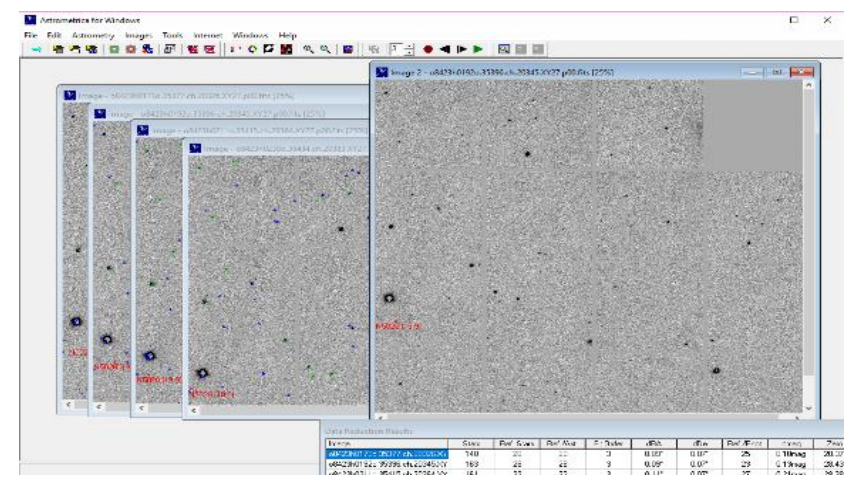

Fig. 6. Moving Objects in the Pan-STARRS-2 Telescope Images.

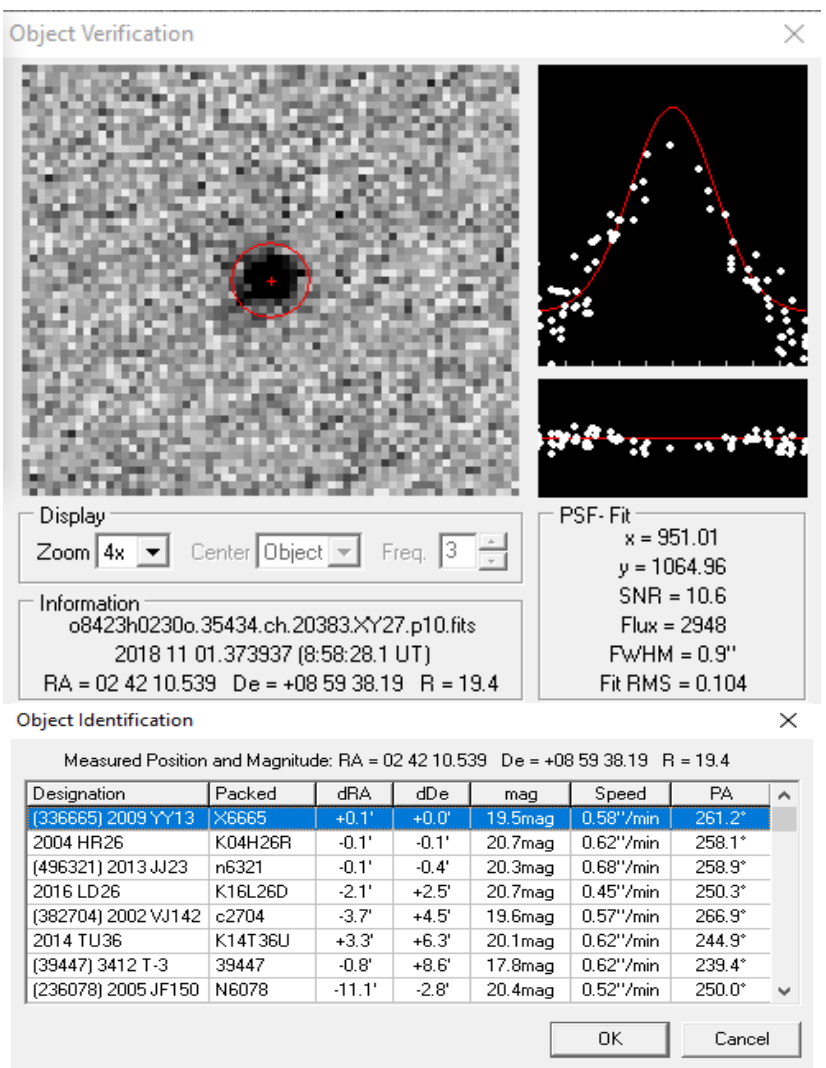

Fig. 7. Astrometric Parameters. 


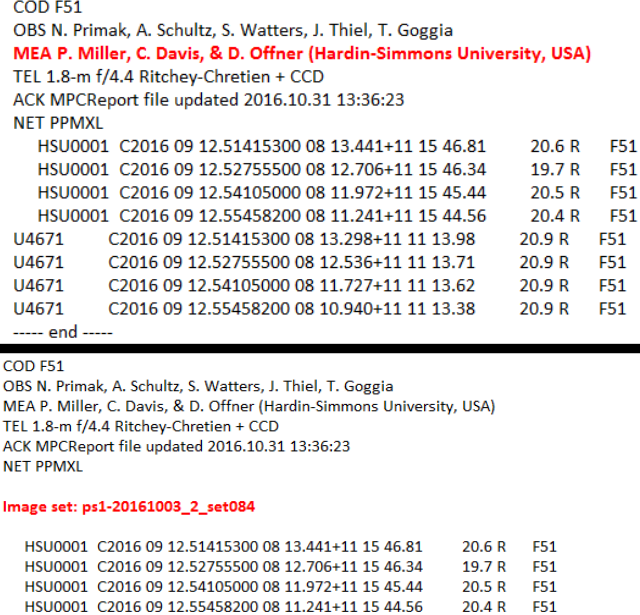

TABLE II. PARTICIPATING TEAMS AND DISCOVERIES

\begin{tabular}{|c|c|c|c|}
\hline$\#$ & Team & Country & Discoveries \\
\hline 1 & Space Girls & Belarus & 1 \\
\hline 2 & $\begin{array}{l}\text { Universidad Mayor de San } \\
\text { Andres }\end{array}$ & Bolivia & 7 \\
\hline 3 & $\begin{array}{l}\text { Municipal center for } \\
\text { extracurricular activities }\end{array}$ & Bulgaria & 6 \\
\hline 4 & Candor Chasma Team & Colombia \& Peru & 12 \\
\hline 5 & Asteroid Caretakers Squad & Colombia-Bolivia & 5 \\
\hline 6 & Ryan's Belt & $\begin{array}{l}\text { Czech } \\
\text { Republic/Slovakia/United } \\
\text { Kingdom }\end{array}$ & 7 \\
\hline 7 & YEHA & Ethiopia & 20 \\
\hline 8 & The Harwoods & France & 22 \\
\hline 9 & $\begin{array}{l}\text { Aristotle University of } \\
\text { Thessaloniki }\end{array}$ & Greece & 10 \\
\hline 10 & SAKED in Space & Greece & 7 \\
\hline 11 & STAR & Greece & 3 \\
\hline 12 & Gagan & India & 5 \\
\hline 13 & Chaitanya Mandala & Italy & 6 \\
\hline 14 & $\begin{array}{l}\text { Rock Hunters Trio - } \\
\text { Bologna University } \\
\end{array}$ & Italy & 11 \\
\hline 15 & $\begin{array}{l}\text { Astro Cypriots - Bekirpasa } \\
\text { Lycee }\end{array}$ & North Cyprus & 6 \\
\hline 16 & $\begin{array}{l}\text { INTI-Lab - Universidad de } \\
\text { Ciencias y Humanidades }\end{array}$ & Peru & 28 \\
\hline 17 & AstropILO & Philippines & 8 \\
\hline 18 & $\begin{array}{l}\text { Institute Of Astronomy Sri } \\
\text { lanka }\end{array}$ & Sri Lanka & 8 \\
\hline 19 & Sky Trailblazers & Sri Lanka & 6 \\
\hline 20 & ULKA & Sri Lanka & 16 \\
\hline 21 & University of Khartoum & Sudan & 13 \\
\hline 22 & Azteroids & USA & 9 \\
\hline 23 & Paco to the Stars & USA & 4 \\
\hline 24 & HSU & USA & 1 \\
\hline
\end{tabular}

It is clear to take into account these parameters because many times it can be confused with hot pixels, background fluctuations with asteroids. Not all things that seem to move in the images will be asteroids.

Step 7: As seen in Fig. 8, once the analysis of the set of images is finished, a report of the discoveries must be made. This report is quite simple because the software elaborates it automatically. The only thing that we must do is to copy the MPC report in a notepad (it must take as name the set of analyzed images) that later we will send to an e-mail to Dr. Patrick Miller, who will be in charge of confirming or discarding a newly discovered asteroid.

\section{RESULTS}

As can be seen in Table II, during the asteroid search campaign October-November 2018, the results of each participating team are shown.

To have found this amount of asteroids in a single team representing Peru is very gratifying because as we observed in other participating countries, there were 2 or 3 teams for each country that means that there is a greater interest in discovering what is in space. When one finds an asteroid brings with it a lot of information, as there is a greater interest in a country, it is possible to get a higher amount of participating teams, and that implies a greater amount of discoveries.

One can see in Table III the number of countries and the total number of asteroids discovered in the preliminary phase, each year, different countries join this campaign, making their interest in exploring space more evident.

In Fig. 9, one can see the report that is sent each week to Dr. Patrick Miller. In the period of the campaign, it was received a set of weekly images, each set had 4 pictures, so in total was obtained a total of 20 images in the search stage. During this period 48 possible asteroids were sent in the report.

TABLE III. COUNTRIES AND THEIR DISCOVERIES

\begin{tabular}{|l|l|l|}
\hline$\#$ & Country & Discoveries \\
\hline 1 & Sri Lanka & 30 \\
\hline 2 & Perú & 28 \\
\hline 3 & France & 22 \\
\hline 4 & Greece & 20 \\
\hline 5 & Ethiopia & 20 \\
\hline 6 & Italy & 17 \\
\hline 7 & USA & 14 \\
\hline 8 & Sudan & 13 \\
\hline 9 & Colombia \& Perú & 12 \\
\hline 10 & Philippines & 8 \\
\hline 11 & Bolivia & 7 \\
\hline 12 & Czech Republic/Slovakia/United Kingdom & 7 \\
\hline 13 & Bulgaria & 6 \\
\hline 14 & North Cyprus & 6 \\
\hline 15 & India & 5 \\
\hline 16 & Colombia-Bolivia & 5 \\
\hline 17 & Belarus & 1 \\
\hline & & \\
\hline
\end{tabular}




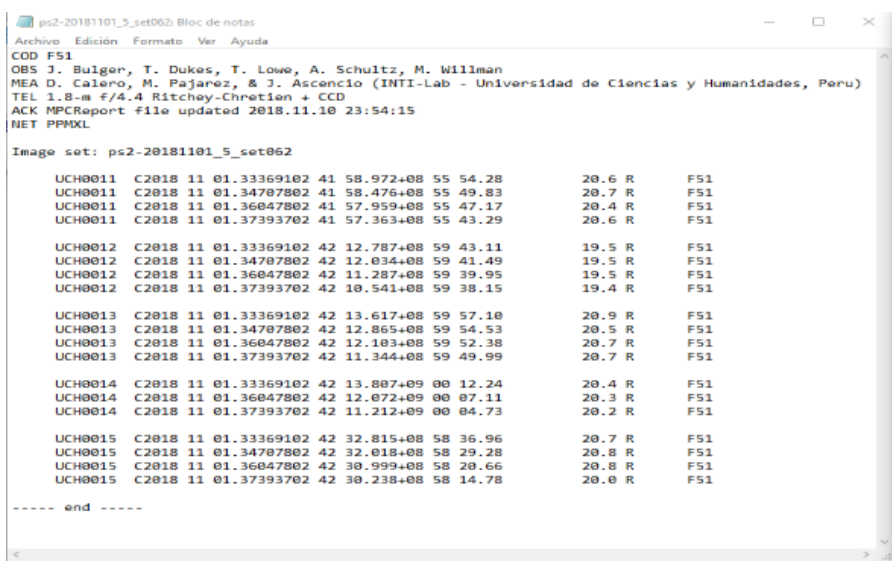

Fig. 9. Minor Planer Center(MPC) Report Model of New Discoveries Report.

According to the results of the International Astronomical Research Collaboration (IASC), as can be seen in the Fig. 10, who had the most considerable number of discoveries was Sri Lanka with its three teams together achieved 30 accepted asteroids in the preliminary phase, then representing Peru our team INTI-Lab - Universidad de Ciencias y Humanidades who obtained 28 accepted asteroids in the initial stage.

These data are beneficial to determine the orbits of objects with greater accuracy or even, as in our case, to make discoveries of new asteroids.

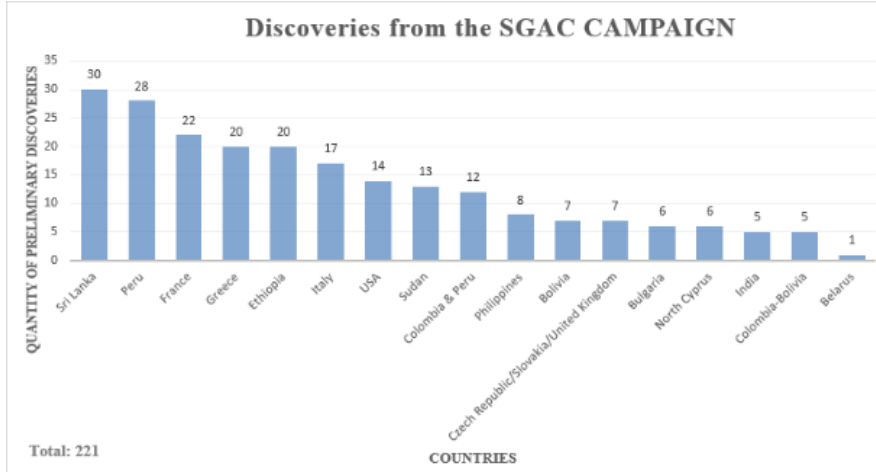

Fig. 10. SGAC Campaing Discoveries.

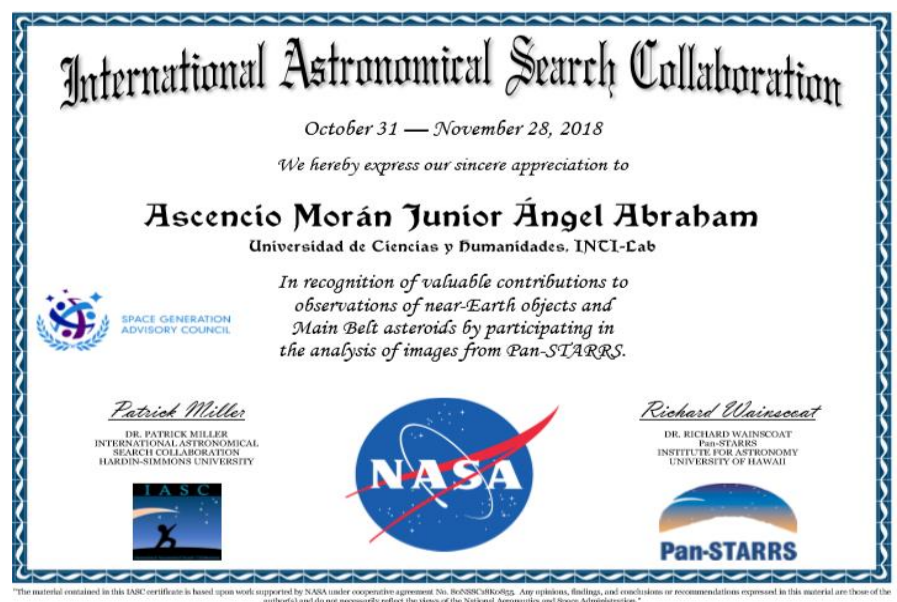

Fig. 11. Certificate for having Participated in the Asteroid Search Campaign..
At the end of the campaign, participants receive an email from IASC which sends them a certificate via email, as can be seen in the Fig. 11, thanking them for their time, effort and dedication during the search stage.

This opportunity to make discoveries and contribute to the goals of protecting Earth from asteroid collisions and exploring new and/or potentially dangerous asteroids is a unique experience, which can be voluntarily accessed.

\section{DISCUSSION}

To send us the set of images from the Pan-STARRS telescope located in Haleakala, Hawaii has to be completely clear otherwise it will not be able to send the collection of pictures to our team during the first four days of having started the campaign. Due to Hawaii, where the telescope that provided the photos is located, had storms with clouds; it was impossible for the telescope to take images for sending us to analyze them.

During the four weeks in which the report of the 48 possible asteroids found was sent, from which 20 steroids were rejected, 28 have been accepted in the preliminary phase.

The Minor Planet Center requires from 7 to 10 days to analyze the preliminary discovery and to confirm its existence and better establish its orbit [10].

Now the nomination stage takes between three and six years since the Minor Planet Center (MPC) updates the preliminary discovery as an interim discovery and monitors additional discovery observations until the orbit has been determined.

Under the direction of instructors, participating students have successfully discovered new asteroids in the preliminary phase of the Main Belt, this is the result of constant motivation and dedication that any person, student or amateur can achieve, through this work motivates people who can participate in future campaigns.

\section{REFERENCES}

[1] Anguita, F., \& Castilla, G. (2005). Crónicas del sistema solar. Recovered from: https://ebookcentral.proquest.com.

[2] Carrasco, L. E., \& Carramiñana, A. A. (2005). Del sol a los confines del sistema solar. Recovered from: https://ebookcentral.proquest.com.

[3] Equipo, S. (Ed.). (2009). Astronomía $n^{\circ}$ 144. Recovered from : https://ebookcentral.proquest.com.

[4] Jorge, R \& Ángel, G. (2008). Astronomía contemporánea (3a. ed.). Recovered from: https://ebookcentral.proquest.com.

[5] Fierro, J., \& Herrera, M. Á. (1988). La familia del sol. Recovered from: https://ebookcentral.proquest.com.

[6] Agencia Espacial del Perú CONIDA (2011), Asteroides Recovered from: http://www.conida.gob.pe.

[7] Space Generation Advisory Council. (2018). SGAC Asteroid Search Campaign. Recovered from: https://spacegeneration.org.

[8] IASC International Astronimical Search Collaboration. Astrometrica. Recovered from: http://iasc.hsutx.edu.

[9] J. Patrick Miller, Jeffrey W. Davis, Robert E. Holmes, Jr. Harlan Devore, Herbert Raab, Carlton R. Pennypacker. (2008). Internet-Based Hands-On Research Program for High Schools andColleges, in Collaboration with the Hands-On Universe Project en Astronomy Education Review vol 7.

[10] USA HOU (2018). IASC participate. Recovered from: http://handsonuniverse.org. 